\title{
NEW TRENDS IN HRM \& KNOWLEDGE MANAGEMENT IN THE HEALTH SECTOR BEYOND COVID-19 - A PRACTICAL MODEL
}

\author{
Mohammed Meri \\ Strasbourg University - Laboratoire Sage, Strasbourg, France \\ mmmeri@unistra.fr
}

\begin{abstract}
The world of work and the status of the human being is constantly changing by the influence of new technologies and the contributions of scientists and practitioners of HRM; therefore, the human being is currently considered as a wealth and its value is maximized. Economists have called it (human capital), accountants (human assets), while contemporary managers have called it (knowledge capital). This change has occurred in the perception of HR due to the transformations that affected the work process began with the TIC revolution of the 21st century, which is concentrated on creativity, innovation based on Competencies to achieve total quality and well-being. But globalization, by for-profit companies, has prioritized profit and the values added to the detriment of which weakened the existence of medical organizations and their personnel as revealed by the Covid-19. Currently, political leaders in the democratic world are turning their eyes and considering human strategies that protect human and open the doors of health protection. Strategic and innovative leadership move on to the development of preventive management which concentrates its priority investments on the KM. New HRM trends, knowledge management (KM) and transformational organizations have become a "strategic" investment as an option in institution building and in health organizations. This new approach adopts the method of KM, competency management in HRM in order to achieve a high-level performance of merit characteristics, efficiency and effectiveness, which combine (motivation, constant incentive, qualities of excellence, clear self-orientation, indepth and up-to-date knowledge and competencies, ...). This paper presents the subject of new trends in HRM and $\mathrm{KM}$ in the health sector as well as the principles of these trends, European, Canadian and American application models, it offers a practical model aimed at improving the health system after Covid-19, in close relation with the improvement of HRM.
\end{abstract}

Keywords: New Trends in HRM, Knowledge management, Health Sector, Covid-19.

\section{INTRODUCTION AND LITERATURE REVIEW}

People are the most important asset for every organization. Knowledge-based enterprises, efficient organization; the rising costs of managing employee health and attracting talent are important trends that require further exploration and development of a healthy HRM and organizational approach in today's workplace. The topic of health and well-being in organizations has recently aroused major interest in research in scientific and applied management (Mayer and Boness, 2010). Health organizations see their talent pool as a major asset and therefore focus their efforts on developing 


\section{Meri, M.}

human resources more effectively. They create and implement policies and practices and make it available to their employees (Guest, 2002).

Davies et al. (2003) defined: health is based overall person and encompasses the emotional, intellectual, spiritual, professional, social and physical dimensions of individuals. The World Health Organization defines health as "a state of complete physical, mental and social well-being and not just the absence of disease or infirmity" (World Health Organization, 2002). Healthy work is likely to be the one where the pressures on employees are appropriate based on their abilities and resources, the amount of control they have had over their work, and the support they receive from the people who count them. This may include an ongoing assessment of health risks, the provision of appropriate information and training on health problems, the availability of organizational support practices and structures for the promotion of health (WHO, 2007).

These HRM practices are the most likely visible factor that helps determine how employees live life within organizations and resonate an organization's commitment to the well-being of its members (Baptiste, 2008). Current work is mainly knowledge-based, offering increased responsibility, better compensation and higher learning opportunities; accelerated work, the demand continues to learn and use newer technologies, and the reduced interaction between people, cause great stress to employees, place higher demands on the well-being of employees and on the health and efficiency of organizations. This is especially true for people working in a knowledge-intensive work environment today.

Recent trends in HRM and work organization can affect workers' health in a variety of ways by increasing the risk of stress-related illnesses or by affecting occupational health services and training programs. Much remains to be learned about the nature of changes in work organization and how they affect the health and safety of workers (Landsbergis, 2003).

The concepts of managerial health were highly individualistic and not related to the workplace and the organization. However, the lifestyle and environment of managers strongly influence their management concepts in health (Botha and Brand, 2009).

Therefore, the call for management from the people's side of organizations such as "healthy organization" does not come as a surprise. HRM has changed in response to a series of economic, technological, legal, political and socio-cultural forces around the world which creates a complex effect on markets, organizations and individuals (Ahuja and Bhattacharya, 2011).

As health reform continues to unfold, CEOs and hospital boards are re-evaluating all aspects of operations, including the structure of their senior management teams. To help illuminate the changing nature of DHS, the American College of Healthcare Executives (2014) collaborated with researchers at Rush University to develop and implement a national survey of high-level teams in independent 
community hospitals in October - December 2013. The results of the survey indicate a considerable variety in the structure of the senior management teams of the autonomous community hospital. This reflects that the size and composition of DHS can be influenced by the organization's mission, structure, size, needs, resources, history and, in some cases, willingness to make the most of talents of specific individuals (Leslie and Garman, 2014).

Leadership is a fundamental part of effective care and nurses are recognized as leaders in patient care. Nursing involves the implementation of goal-oriented interventions aimed at improving the patient's health or comfort. The head nurse plays an essential role in the affairs of the health care organization and the quality and safety of the services provided (Huber, 2010). For decades, American hospital administrators and healthcare professionals have operated in a demanding, fast and fragmented healthcare system. Today, this environment is even more complex as health reform and market forces are transforming the way health care is administered and managed. This profound change is both structural and cultural. New alliances and unlikely partnerships are beginning to emerge. Belief systems, values and attitudes change. Creative thinking and agile and adaptable leadership will be needed to make hospitals, health systems and networks sustainable as the healthcare delivery landscape changes. Rapid innovation and adaptation to change require a culture and collaborative and interdependent solutions that cover function, region and profession. Leaders need to learn how to move away from the "individual expert" model so common in today's health systems and move towards a model that takes advantage of boundary groups and teams and covers disciplines, levels, functions, generations and professions (Browning et al., 2011).

In Canada, the medical care provided by doctors and others should be aligned around the values and needs of patients. Address the health care needs of Canadians in the most comprehensive, effective and efficient and collaborative manner. Collaborative care teams should foster and support patients and their families as active participants in decision-making health care. Collaborative models of health care delivery hold the promise of improving patient access to care in the event of a severe shortage of health human resources. Governments and policy makers must continue to intensify their efforts to increase the number of doctors and nurses available to provide health care services.

PEPFAR (The President's Emergency Plan for AIDS Relief) approves a capacity building framework that addresses three integrated and strengthening components: (individual / personal, organizational and systems in a country context, WHO, 2012).

Australia's healthcare system faces several complex and interconnected challenges to deliver high quality, innovative and cost-effective care in the future. These include an aging population increasingly affected by chronic diseases, rising health care costs, technological change and the need to improve equity and accessibility of the health system, the need to maintain and improve safety and quality will be 


\section{Meri, M.}

a permanent priority. This will require a change in the way health care is provided, models of care, and the role of all members of the health workforce (Australian College of Nursing, 2015).

In Europe, currently, European states live in a globalized and rapidly transnational world, which increases the demand for cooperation between communities towards public health. The scope of the action goes far beyond health and medical care as envisaged by the main political tool of the Health 2020 strategy, the new European political framework and the strategy for better and more equitable population health in the region embodies rigorous plans. This initiative was adopted unanimously by the 53 Member States of the WHO European Region in 2012. Recognizing that Health 2020 is a general policy and strategy that provides a common vision and includes key strategic directions, including for strengthening public health capacities, it recognizes that each Member State must define its own starting point. This new architecture of European public health governance has increased the number and diversity of actors involved in decision-making (Rechel and McKee, 2014).

WHO and ILO joined forces very shortly after the formation of WHO, to the Joint ILO / WHO Committee on Occupational Health, recognizing the importance of these issues. It is relatively recently, however, that health promotion has been specifically linked to the workplace. The US National Institute for Occupational Safety and Health (NIOSH) has a Work Life initiative that "envisions safe workplaces recognized, and support policies, programs and practices; and employees have easy access to effective programs and services that protect their health, safety and well-being. Moreover, the control or computerized monitoring of work is the constraint of rhythm that has spread the most. Over the same period, employees report greater opportunities for cooperation with their colleagues or management, which may mitigate the effects of intensification.

Globally, there are new and diverse political, technical and financial frameworks that shape the understanding, delivery and evaluation of public health in our societies. Public health professionals need to acquire competencies to reach the whole society where the important determinants of health (working conditions, education and the environment, and offer practices and opportunities for create new structures, partnerships and networks). Public-private partnerships are increasingly seen as playing an essential role in improving the performance of health systems worldwide by bringing together the best features of the public and private sectors to improve efficiency, quality, innovation and the impact on health of private and public systems (Mitchell, 2013).

The European states must implement a very effective policy and action plans to face the wave of the Covid-19 and cooperate to achieve together this common strategy of Europe 2020 and beyond. 


\section{PROBLEMATIC AND OBJECTIVE OF THE RESEARCH}

The objective is to improve the health sector remains very important for the current health discussion and to provide individual organization actors efficient tools that help in the decision-making process to share and exchange and practice on health information's. The improvement of the qualities of care, participating in a local or national health system is an important step for organizations that want to establish databases to improve (patient safety, quality of care and lower the cost of health-related activities). In a few countries, the health care system has been slow to transform itself as much as at organizational levels about HRM. A new approach is trying to bring together managerial models in order to become more useful; and offer elements of a sustainable model that will help transform the health sector to be more efficient and adequate, especially after COVID-19 pandemic. Currently, there are multiple models used in the health sector.

\section{CONCEPTUAL FRAMEWORK}

The conceptual framework of the paper is presented such as:

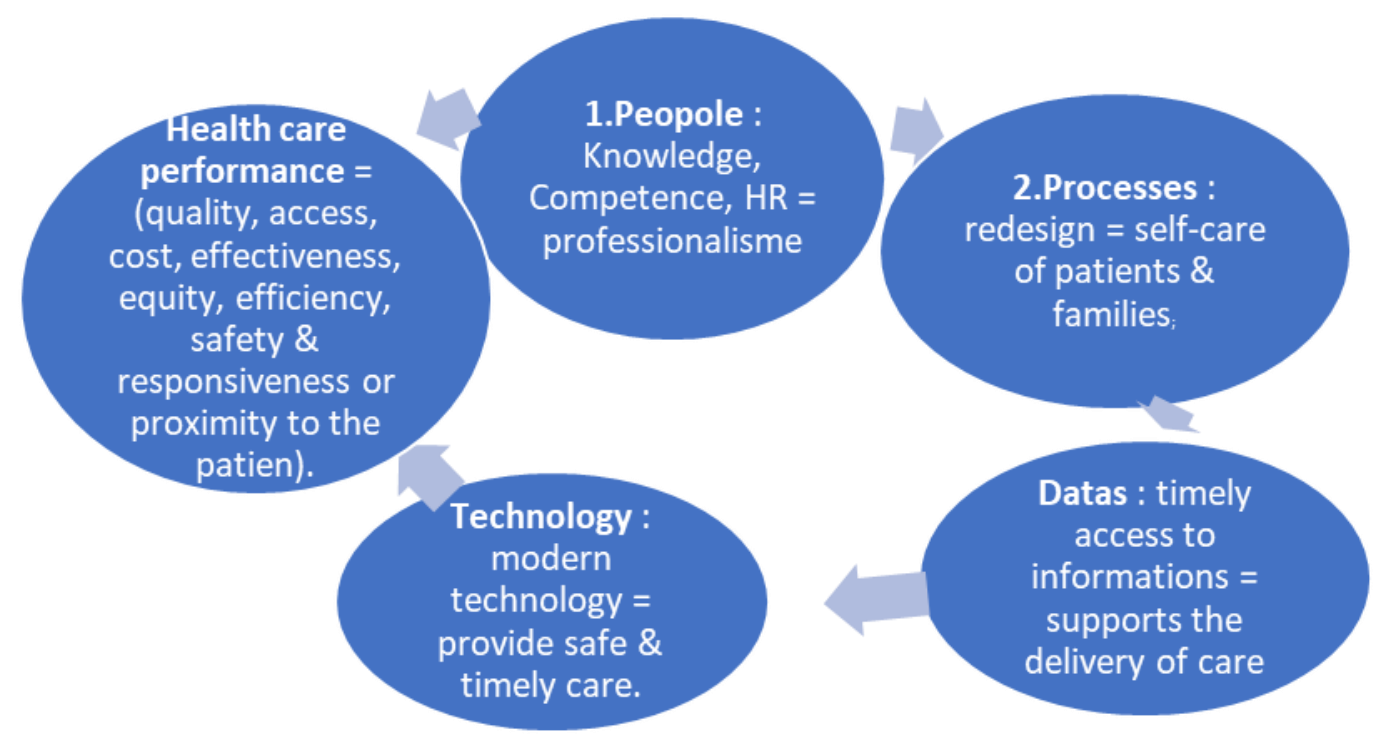

FIGURE 1. CONCEPTUAL FRAMEWORK

Source: The author 


\section{GENERAL PRINCIPLES OF WORK IN HEALTH}

\subsection{The principles of WHO and UN}

In the late 1980s, WHO and other United Nations agencies broadly accepted several basic principles for international health work such as:

1. Health work in any country is done according to national regulations;

2. All civil servants must be devoted solely to the agency in which they work;

3. A health agency must respond to requests for help,

4. Healthy people can contribute more effectively to national productivity than people with disabilities through diseases and disabilities;

5. The health of the population is influenced by all social sectors, not only by health services;

6. The highest priority should be given to the problems which affect the greatest number of people.

7. Health policies should promote national health systems that ensure the equitable distribution of health services to all people;

8. Health work is a growing concern for all health services worldwide.

In the modern world, the claim that "disease knows no borders" has become a (cliché) that cannot be repeated. The goal today is to ensure in all countries - rich or poor, large or small - the health benefits of modern science and civilization. In this reality, the goal of global health means that everyone in every country will have the same chance of achieving the highest possible level of health (Bynum and Porter, 2008).

\subsection{The Principles of Team-Based Health Care}

Health care has changed dramatically in the past 20 years. Since then, the pace has accelerated even more. The speed of change will continue to accelerate as clinicians and patients integrate new knowledge and technologies into their management of well-being, disease and complicated aging. In practice, team-based health care is the provision of health services to individuals, families and / or their communities by at least two health care providers who work collaboratively with patients and their caregivers to the extent preferred by each patient to achieve shared goals within and across settings to achieve coordinated, high quality care. Here are the five personal principles values that characterize the most effective members of high-level teams in health care (Mitchell et al., 2012).

TABLE.1. THE FIVE PERSONAL PRINCIPLES VALUES OF THE MOST EFFECTIVE TEAM MEMBERS

\begin{tabular}{|c|l|}
\hline Team values & \multicolumn{1}{|c|}{ Description } \\
\hline Honesty & $\begin{array}{l}\text { Honesty is critical for continuous improvement and to maintain mutual trust in a } \\
\text { high-level team. }\end{array}$ \\
\hline
\end{tabular}




\begin{tabular}{|c|l|}
\hline Discipline & Discipline allows teams to develop; comply with their standards and protocols. \\
\hline Creativity & $\begin{array}{l}\text { Team members are excited about the opportunity to creatively tackle new or } \\
\text { emerging issues. }\end{array}$ \\
\hline Humility & $\begin{array}{l}\text { Working in a team is that these members can support each other to help recognize } \\
\text { and avoid failures. }\end{array}$ \\
\hline Curiosity & $\begin{array}{l}\text { Team members are dedicated to reflecting on the lessons learned in their daily } \\
\text { activities and using the ideas for continuous improvement in their own work. }\end{array}$ \\
\hline
\end{tabular}

Source. Adapted from Mitchell et al., 2012

As well as the principles of team-based health care must be complemented by:

- Shared objectives: the team (the patient, family members or other support persons) works to establish common objectives that reflect the priorities of the patients and the family, supported by all members of the team.

- Clear roles: there are clear expectations for the roles, responsibilities and responsibilities of each member of the team, which optimize the common effectiveness.

- Mutual trust: team members gain trust from each other, creating strong standards of reciprocity and better chances of shared success.

- Effective communication: the team favors and perfects coherent channels for transparent and complete communication, accessible and used by all members.

- Measurable process and results: the team implements reliable comments on successes and failures in the functioning and achievement of the team's objectives (Mitchell et al., 2012)

\section{MODELS OF WORKING IN HEALTHCARE}

\subsection{Health information exchange models (HIE)}

The Healthcare Information and Management System Society (HIMSS) has described the different models implemented across the country and the different standards to be considered. Having basic information supports the use of a guide when evaluating joining a Heath Information Exchange HIE). Participating in an HIE requires stakeholders to make a difference. Stakeholders who may be interested in providing or obtaining information from an HIE are defined according to different models; Each presents interoperability, development and sustainability issues, as well as privacy and security concerns for health care settings, clinical providers and patients. The Models are:

5.1.1. The centralized model. In a centralized model, patient health data or medical data are collected from local sources but stored in a central repository. 


\section{Meri, M.}

5.1.2. The decentralized or federated model. This model provides organizational control of the health record and provides a framework for the ability to share data with businesses, and widely distributed across regions or even nationwide.

5.1.3. The hybrid models. This model has a centralized and decentralized architecture. It provides the interface engine for which the organizational units of the HIE communicate.

5.1.4. The health records bank model. The model strives to control the consumer with respect to those who can access their file housed in a central system depot.

5.1.5. International models. Canada Heath Info way is a national initiative to interconnect systems in all provinces and territories. Canada Health Info way is an independent, not-for-profit organization funded by the federal government that accelerates the development of electronic health records across Canada.

5.1.6. State-based and community-based models. State-led HIE models promote the exchange of information for the common good and encourage, promote and facilitate the creation of a regional exchange of information data.

5.1.7. Business models. The Deloitte Center for Health Solutions highlights four basic business models in which HIEs operate. While not-for-profit business models appear to dominate the HIE industry, longterm financial sustainability and governance continue to be major issues. As with all businesses, a wellthought-out business plan must exist, including start-up operational costs as well as sustainable revenue for ongoing off-service operations (HIMSS, 2009).

\subsection{Partnership model (public / private) in healthcare}

Three main reasons are that health partnerships have become a major force in health care. It is a change of philosophy on the roles of the sectors (public and private); Recognition by the public and private sectors of their interdependence; and a better understanding of how each party can benefit from a partnership. Public-private partnerships are increasingly seen as playing a critical role in improving the performance of health systems worldwide by bringing together the best characteristics of the public and private sectors to improve efficiency, quality, innovation and the impact on health of private and public systems. In this model, the predominant forms of partnership are found in the two shaded boxes. These are the partnership models:

5.2.1. Model 1. The private sector provides funding, the public provides services.

5.2.2. Model 2. The public sector finances and the private sector provides services. 
The two most common models of this type are contracts and insurance programs. Most governments have long experience in providing health services often in rural areas with religious groups but are developing more and more partnerships with for-profit groups to provide services (Mitchell, 2013).

\subsection{The Integration Model (GAT / TQM / AQ / QI) In the WHO paradigm}

To have a healthy workforce, the workplace must be secure, offer good ergonomic design and provide working conditions that help ease the stress of health work. If properly implemented and institutionalized, GAT / TQM / $A Q / I Q / I Q$ can serve as a mechanism to transform a health care organization into a WHO / HWO. To guide future research, a framework is proposed that links EI research with WHO research in the belief that QA / IQ methods and interventions could be an effective way to create a WHO. Areas should focus on identifying the organization of work, cultural, technological and environmental factors that affect the processes of care; affect health, safety and patient satisfaction and indirectly affect the health, safety and satisfaction of patients through their effects on staff and variables in the care process (Sainfort, 2001).

\section{HRM, KM AND IMPROVEMENT OF THE HEALTH SECTOR}

\subsection{The interaction between health, safety at work and productivity}

It is well recognized that health positively influences economic well-being, growth and wealth. The reverse influence is also well recognized. Countries would certainly perform better in the absence of disease, particularly at the individual and family levels. The economic impact of chronic diseases can be estimated and projected by analyzing specific channels through which chronic diseases influence economies. However, income (for example, GDP) is the ultimate link on the socio-economic effects of chronic diseases, so that practical outcome measures can be used to estimate the economic impact of chronic diseases (Abegunde and Stanciole, 2006).

\subsection{Capacity Building, Knowledge Management and the sustainable impact of health}

Capacity is the ability of individuals and organizations or organizational units to perform functions effectively and sustainably. Effective capacity building efforts are directed at government, local research and development institutions, non-governmental organizations, networks, communities, academia and the private sector, with the aim of improving the knowledge, the potential for short and long term long term of these institutions to support local and government response, and to manage and monitor internal and external efforts to control disease in the country. PEPFAR approves a capacity building 
Meri, M.

/knowledge management framework that addresses three building components (individual / workforce, organization and systems) in a country.

\subsection{Building bridges to team-based care activities}

Building bridges between these activities can help ensure synergy and efficiency. Here, we highlight the links between team-based care and three areas in particular: interprofessional education, workforce development health informatics, and care coordination (Mitchell, 2012). Workgroups focus on the health care workforce and ways to improve the quality of care it provides. A healthy workplace is one in which workers will be able to provide better quality care and in which workers' health and high-quality patient care are mutually reinforcing (Eisenberg et al., 2001). The goals and objectives of the executive and management align with the strategic direction of the health system. The British Columbia Ministry of Health in Canada has published and implemented health system strategy: a collaborative and interestbased approach that they also harmonize with the three general objectives of the triple objective (developed by the Institute for Health Improvement):

1. Improve the health of populations;

2. Improve the patient's experience with care.

3. Reduce the per capita cost of health by focusing on quality.

The health system proposes a conceptual model for (GRHS / HHRM) and the evaluation of this conceptual model is based on micro (practical), meso (organizational) and macro (provincial) contextual descriptions commonly used in the social sciences. These inputs or levels of analysis are not isolated from each other; most often, they interact across the three levels:

- The micro-layer is where the efforts to deploy HR in health for operational service planners materialize in the form of an individual and teamwork design.

- The meso layer, service delivery is affected by interventions that take place at the organizational level, often but not always through HR services.

- The macro layer, service delivery is affected by the province's health HR infrastructure; Such as health professional education, accreditation and regulation.

The HRH deployment model focuses on the staff mix and knowledge management. The most common approaches for optimizing the composition of staff allow adjusting the number of staff, pooling qualifications, balancing junior and senior staff (experience) and mixing disciplines. The staff mix in primary care teams typically includes nurses, doctors, specialists, pharmacists and social workers, nonclinical staff and volunteers. 


\subsection{The Challenges of HRM in Health}

HRM in health poses the greatest strategic challenge of all, for health systems, for at least four reasons such as:

6.4.1. Health care consists of a large and complex system of groups of health service providers and organizations that represent, regulate or employ them.

6.4.2. The effective execution of a health HR strategy requires cooperation and coordination within this vast and complex system.

6.4.3. The challenge of providing a distributed service delivery system in a large geographic region; which includes cities and rural communities.

6.4.4. The challenge of anticipating and responding to future health human resource needs.

In these areas, the basic logic of the health system begins with achieving significant results for the health of the population and individual patients. Results focus on actual health outcomes and the quality of the healthcare experience:

TABLE. 2. THE HEALTHCARE OUTCOMES AND THE QUALITY OF THE HEALTHCARE EXPERIENCE

\begin{tabular}{|c|l|}
\hline Results & \multicolumn{1}{c|}{ Description } \\
\hline Effectiveness & Treatments that are known to achieve the expected results. \\
\hline Suitability & The care provided is based on evidence and specific to individual clinical needs. \\
\hline Accessibility & Ease with which health services are reached. \\
\hline Safety & Avoid damage resulting from treatment. \\
\hline Acceptability & $\begin{array}{l}\text { Care that respects the preferences, needs and values of patients and their } \\
\text { families. Two other dimensions of quality measure the performance of the system } \\
\text { in which health services are provided: }\end{array}$ \\
\hline Equity & $\begin{array}{l}\text { Distribution of health care and its benefits equitably according to the needs of the } \\
\text { population. }\end{array}$ \\
\hline Efficiency & Optimal use of resources to maximize benefits and results. \\
\hline
\end{tabular}

Source: Adapted from Kabene et al., 2006

\section{THE NEW TRENDS IN (HRM, KM) IN HEALTH/HRMH}

An aligned strategy in a complex sector such as health requires a framework to understand and coordinate action.

\subsection{A conceptual framework for HRMH}

This framework also allows us to recall the magnitude of the factors that have an impact and are affected by HRMH. Such capacity should extend through the micro, meso and macro levels of the 
Meri, M.

system. There is a potential vehicle to drive this agenda using provincial collaboration for leadership development in the system. The MOCINS collaborative care model includes four key attributes intended to serve as a lever for change to build a conceptual framework such as:

7.1.1. People. Having the right people to do the right job, working together in interprofessional teams in which the role of health care providers is optimized to meet the needs of patients and their families;

7.1.2. Processes. Redesign processes to eliminate waste, prevent duplication by the health care team and allow self-care for patients and families;

7.1.3. Information. Ensuring timely access to information that supports the delivery of care, research and academic mandates;

7.1.4. Technology. Using modern technology to provide safe and timely care.

The model does not prescribe specific processes or practices, it is left to the units to apply these four attributes locally, in a manner appropriate to their unique context. Canada. British Columbia (Ministry of health, 2015).

\subsection{The European framework and health policy}

The new European health policy framework (Health 2020), adopted by the Member States of the WHO European Region in September 2012 in Malta, highlighted the need for action in public health, including through intersectoral policies (WHO 2012b). One of its main pillars is the European Action Plan for Capacity Building and Public Health Services (WHO 2012a), also adopted in Malta, which in turn builds on the 2008 Tallinn Charter (WHO 2008). The framework has two main objectives:

1) Provide a description and analysis of existing public health structures, capacities and services in Europe.

2) Define, as far as possible, what structures, capacities and services would be needed to strengthen public health action.

In other cases, European countries have made political commitments to improve the delivery of public health functions in documents such as the 2012 European Action Plan for Strengthening Public Health Capacity and Services, which approved by the 53 Member States of the WHO European Region. The European Action Plan for Capacity Building and Public Health Services (WHO 2012a) contains ten elements. Therefore, public health in Europe should be in a continuous flow Europe is changing and with it both the threats to the health of the population and the opportunities to respond to them. The key trends to take into account for future action is that European public health must take a broad perspective, putting into practice its long-standing commitment to promoting health in all policies. Mackenbach and McKee (2013), The European Observatory on Health Systems and Policies (2014). 


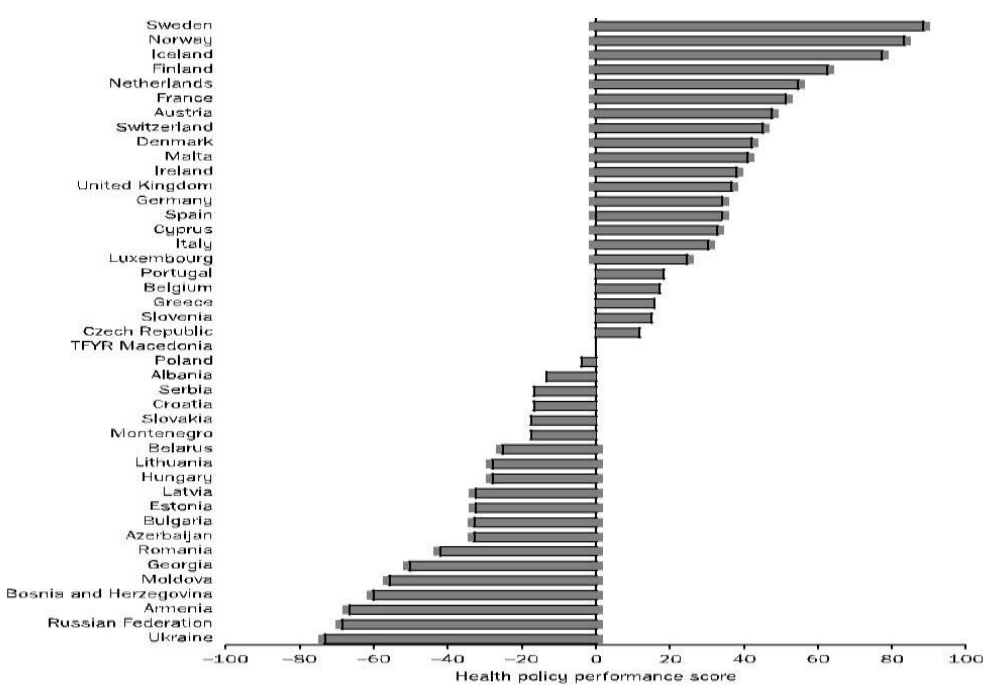

FIGURE 1. PERFORMANCE ON A COMPOSITE MEASURE OF HEALTH POLICIES IN EUROPE

Source: Mackenbach and McKee (2013).

\section{RESULTS}

As a result, there are some models for improving the HRM in Health sector such as:

\subsection{The conceptual framework proposed for the OECD- HCQI project}

The OECD- HCQI conceptual framework optimizes the project's emphasis on technical quality of health care while maintaining a broader perspective on health and its other determinants. This framework suggested for the project takes the dimensions of care most commonly used in the frameworks studied and integrates them into a model that borrows a lot from the framework of national indicators of quality of health care of the Institute of Medicine developed for United States. The framework provides a visual summary of the dimensions of health care performance, including (quality, access, cost, efficiency and equity). It also presents a visual picture of factors related to the performance of the health system, but distinct, such as: "the design, policy and context of the health system; Non-health, Determinants of health and overall levels health". Finally, it highlights the specific dimensions of the quality of care that will focus on the HCQI project, efficiency, safety and responsiveness or proximity to the patient (OECD, 2020).

\subsection{New HRM trends, KM in the health sector}

Human capital and knowledge management are widely recognized as the key ingredient for productivity 
and innovation in a knowledge-based economy. HRM practices in companies are essential for the development and use of human capital. The main work trends of the last decade - work intensification, organizational restructuring, work-life imbalance - aim to achieve these objectives. Employers and health care providers are concerned about (rising costs of prescription drugs and disability claims, hospitalization and related medical services, absenteeism and low death due to conditions stressful work). These trends contain Health, Work and Productivity Outlooks such as:

8.2.1. Well-being in the workplace; Well-being in the workplace emerged in the 1990 s as a major concern for employers.

8.2.2. Healthy Organizations; A health promotion that increasingly demands a holistic approach that addresses the underlying organizational and organizational factors.

8.2.3. Health and productivity; there is the relationship between healthy work contexts and organizational rather than individual outcomes. Productivity, or organizational performance, is a set of results.

8.2.4. Factors and productivity of the workplace; these are the link "healthy work - productivity" on the productivity side, the current reflection on human capital contributions to overall productivity at the enterprise level.

\subsection{HRM and collaborative work in the health sector}

Public, private and non-profit institutions and organizations often work together in a coalition with communities, neighborhoods and electoral districts. This collaboration is related to three other strategies for working together: (networking, coordinating, and cooperating that accumulate along a continuum of development). These strategies are most effective when a common vision and purpose, meaningful power sharing, mutual learning and mutual accountability for results. A matrix on the proposed model provides a summary of the four strategies for working together, with some notes on the structure of the coalition; organization and governance such as:

8.3.1. A coalition benefits greatly from spending the time needed to clearly articulate its mission and goals and reach agreement with them from all stakeholders.

8.3.2. Action groups are wise to only create action plans for which there are specific people and organizations to carry them out.

8.3.3. All action groups in a coalition use the same format to create an action plan.

8.3.4. Ensure that action groups need facilitation and guidance, as well as some collaborative leadership characteristics.

8.3.5. A desire to actively encourage partners to share their risks, responsibilities, resources and rewards and to thank contributions. 
8.3.6. An ability to balance the need for discussion, information sharing and storytelling with timely problem solving.

8.3.7. Understand the role of community organization as a basis for developing and developing collaborative power.

8.3.8. Active engagement in informal and formal leadership development activities that can take the collaborative process to higher levels of effectiveness.

8.3.9. The ability to communicate in a way that invites comments and suggestions that address problems without attacking people and, where appropriate, relies on conflict resolution and win-win negotiation to resolve differences.

8.3.10. A very good sense of humor, especially when collaborative processes get ugly or boring or both. Historically, organizations have developed strategic plans for three to five years. However, with health reform, new technology and industry staffing issues, the process of strategic planning has become more frequent and rightly so (Bakker et. al, 2008).

\subsection{The Practical Model proposed}

It is a practical model proposed as an added contribution based on the improvement of human resource management and knowledge management to make the health system and the health sector more efficient and effective while drawing lessons from the situation. corvid-19 pandemic that invaded the world.

\begin{tabular}{|c|c|c|c|}
\hline $\begin{array}{c}\text { Needs } \\
\text { patients } \\
\text { and } \\
\text { their } \\
\text { families }\end{array}$ & $\begin{array}{l}\text { HR Care } \\
\text {-Management of individual } \\
\text { competencies; } \\
\text { - Interprofessional teams; } \\
\text {-Perfect management of HR } \\
\text { business: (Recruitment; } \\
\text { Compensation; } \\
\text { Training contained; } \\
\text { Evaluation; } \\
\text { Career and mobility). } \\
\text {-Leadership and developing } \\
\text { competencies. }\end{array}$ & $\begin{array}{l}\text { TIC and Materials } \\
\text { - Install modern } \\
\text { technologies to } \\
\text { provide safe and } \\
\text { timely care } \\
\text {-Exploit } \\
\text { technologies } \\
\text { effectively. } \\
\text {-Preventively } \\
\text { maintain equipment } \\
\text { and TIC Health }\end{array}$ & $\begin{array}{l}\text { Communications and functional } \\
\text { relations } \\
\text {-Access data's in a timely manner. } \\
\text {-Strengthen internal } \\
\text { communications. } \\
\text {-Educate patients \& their families } \\
\text { regarding the medical aspects. } \\
\text {-Improve communication skills } \\
\text { with patients \& their families. } \\
\text { - Using preventive health. }\end{array}$ \\
\hline \multicolumn{4}{|c|}{$\begin{array}{l}\text { Productivity, Performance and improvement: } \\
\text { Adopt indicators to evaluate the results, implement multiple evaluation methodologies, achieve satisfaction } \\
\text { people, continuously improve health work. }\end{array}$} \\
\hline
\end{tabular}

FIGURE 2. THE PRACTICAL MODEL PROPOSED

Source: The author 


\section{CONCLUSIONS}

The conclusions and recommendations, beyond COVID-19 pandemic are:

- Manage the health sector through knowledge and competency management, according to performant management style;

- The organizations of yesterday are turned towards institutions which have clear objectives and flexible organizational structures,

- Contemporary leadership has turned to the innovating strategy, through the transition to continuous improvement, and to preventive health management which concentrates its $H R$ investments in Knowledge Management.

- produce health materials undependably in Europe and in each country to avoid any dependence to other countries out EU.

- The proposed approach is based on the method of applying permanent organizational changes such as: (Innovating logic models in the health sector, Applying new Knowledge Management and HRM trends in health work, Benefiting from good practices achieved in health sector, sharing successful experiences in the health sector in developed and democratic countries, creating one or more models inspired by the national culture of each country to apply it in the health sector).

\section{REFERENCES}

Abegunde, D., \& Stanciole, A. (2006). An estimation of the economic impact of chronic noncommunicable diseases in selected countries. World Health Organization, Department of Chronic Diseases and Health Promotion, 2006.

Ahuja, R, \& Bhattacharya, B. (2007). Healthy Workplace in Corporate Sector- India: An Operational research. Retrieved December, 15, 2009, from http://www.whoindia.org/EN/Section20/Section29_1414.htm

American College of Healthcare Executives (2014). Division of Member Services, Research American College of Healthcare Executives. CEO Circle White Paper.

Australian College of Nursing (ACN), (2015). Nurse Leadership, A White Paper by CAN. ACN: Canberra.

Baptiste, N. R. (2008). The symbiotic relationship between HRM practices and employee well-being: A corporate social responsibility perspective. Aldershot: Ashgate.

Bakker, A. B., Schaufeli, W. B., Leiter, M. P., \& Taris, T. W. (2008). Work engagement: An emerging concept in occupational health psychology. Work \& stress, 22(3), 187-200.

Botha, P. A., \& Brand, H. (2009). Development of a holistic wellness model for managers in tertiary institutions. SA Journal of Human Resource Management, 7(1), 1-10. 
Browning, H. W., Torain, D. J., \& Patterson, T. E. (2011). Collaborative healthcare leadership: A six-part model for adapting and thriving during a time of transformative change. Center for Creative Leadership White Papers.

Bynum, W. F., \& Porter, R. (2008). The World Health Organization and its work (American Journal of Public Health (2008) 98 (1594-1597)). American Journal of Public Health, 98(12).

Davies, J., Davies, R., \& Heacock, S. (2003). A wellness program for faculty. Educational Leadership, 60(8), 68-68.

Eisenberg, J. M., Bowman, C. C., \& Foster, N. E. (2001). Does a healthy health care workplace produce higher-quality care?. The joint commission journal on quality improvement, 27(9), 444-457.

Guest, D. (2002). Human resource management, corporate performance and employee wellbeing: Building the worker into HRM. The journal of industrial relations, 44(3), 335-358.

HIMSS Healthcare Information and Management Systems Society. (2009). A HIMSS Guide to Participating in a Health Information Exchange. HIMSS Healthcare Information Exchange, HIE Guide Work Group White Paper: USA.

Huber, D. L. (2010). Leadership and nursing care management. Missouri: Saunders.

Kabene, S. M., Orchard, C., Howard, J. M., Soriano, M. A., \& Leduc, R. (2006). The importance of human resources management in health care: a global context. Human resources for health, 4(1), 20.

Landsbergis, P. A. (2003). The changing organization of work and the safety and health of working people: a commentary. Journal of occupational and environmental medicine, 45(1), 61-72.

Leslie A. Athey, \& Andrew N. Garman (2014). How Senior Leadership Teams are Changing: A Survey of Freestanding Community Hospital CEOs. Retrieved March 29, 2020, from https://www.ache.org//media/ache/learning-center/research/ceowhitepaper2014.pdf

Mackenbach, J., McKee, M. (2013). The European Observatory on Health Systems and Policies

Mayer, C. H., \& Boness, C. (2010). Managing conflicts in small scale enterprises in the Tanzanian tourist industry. Asia Pacific Journal of Business and Management, 1(2), 31-48.

Mitchell, M. (2013). Aperçu des partenariats public-privé en santé, M.D., M.S. Harvard School of Public Health.

Mitchell, P., Wynia, M., Golden, R., McNellis, B., Okun, S., Webb, C. E., ... \& Von Kohorn, I. (2012). Core principles \& values of effective team-based health care. NAM Perspectives.

OECD (2020). Health Care Quality Indicators. Retrieved March, 24, 2020, from www.oecd.org/.

Rechel, B., \& McKee, M. (2014). Facets of public health in Europe. McGraw-Hill Education (UK).

Sainfort, F. (2001). Where is OR/MS in the present crises in health care delivery. In Institute for Operations Research and the Management Sciences 2001 Annual Meeting, Miami.

The European Observatory on Health Systems and Policies (2014) Facets of Public Health in Europe, Edited by Bernd Rechel and Martin McKee, Open University Press, England).

World Health Organization/ Organization Mondale de la santé (2002). Constitution of the World Health Organization. Retrieved June, 26, 2019, from http://whqlibdoc.who.int/hist/official_records/constitution.pdf.

WHO (2007). Occupational health Stress at the workplace. Retrieved March, 12, from http://www.who.int/occupational_health/topics/stressatwp/en/.

WHO (2012). The President 's Emergency Plan for AIDS Relief. Capacity Building and Strengthening Framework, Version 2.0. Retrieved March 20, 2020, from https://www.who.int/healthsystems/PEPFAR.pdf 